First Peoples Child \& Family Review

A Journal on Innovation and Best Practices in Aboriginal Child Welfare Administration,

\title{
A Story of their own: Adolescent Pregnancy and Child Welfare in Aboriginal Communities
}

\section{Emilia Ordolis}

Volume 3, Number 4, 2007

URI: https://id.erudit.org/iderudit/1069372ar

DOI: https://doi.org/10.7202/1069372ar

See table of contents

Publisher(s)

First Nations Child and Family Caring Society of Canada

ISSN

1708-489X (print)

2293-6610 (digital)

Explore this journal

Cite this article

Ordolis, E. (2007). A Story of their own: Adolescent Pregnancy and Child

Welfare in Aboriginal Communities. First Peoples Child \& Family Review, 3(4),

30-41. https://doi.org/10.7202/1069372ar
Article abstract

The phenomenon of adolescent pregnancy and its relationship to child welfare in Aboriginal communities provides a useful lens through which to understand fundamental and structural problems with the current child welfare system in Canada. The following paper will examine the relationship between adolescent pregnancy and child welfare, investigate concerns with the current child welfare system, and look to the Convention on the Rights of the Child as a framework for conceptualizing alternative approaches.
This document is protected by copyright law. Use of the services of Erudit (including reproduction) is subject to its terms and conditions, which can be viewed online.

https://apropos.erudit.org/en/users/policy-on-use/ 


\title{
A Story of their own: Adolescent Pregnancy and Child Welfare in Aboriginal Communities
}

\author{
Emilia Ordolis
}

\begin{abstract}
Emilia Ordolis is currently completing her law degree at McGill University. Her main areas of research are reproductive health rights and human rights education. Having spent time teaching and doing health promotion overseas, she started a project on the Right to Education through McGill University which focuses on raising awareness about children's rights, and conducting outreach workshops at the elementary-level.
\end{abstract}

\section{Introduction}

Recent reviews of the current discourse on child welfare in Canada have revealed a striking lack of attention to the voices of mothers and children. This silence has been linked to the marked failure of the system to address the systemic drivers of child abuse and neglect (Killington, 2002). Moreover, the absence of personal stories has contributed to a lack of insight into the lives of mothers, into the needs of children, and into the social variables that have led to their encounters with the child welfare system (Killington, 2002). These concerns are particularly relevant in the Aboriginal context, where the effects of the residential school system and assimilationist child welfare policies have led to profound social grief, trauma and dislocation. As one woman explained, her experience reflects an intergenerational cycle; "I never had no parenting skills when I had my kids because I lived in residential school," she recounts, "you never

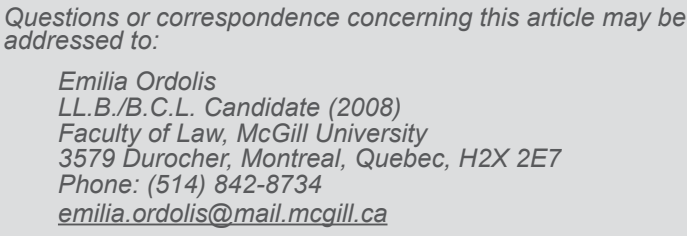

\begin{abstract}
The phenomenon of adolescent pregnancy and its relationship to child welfare in Aboriginal communities provides a useful lens through which to understand fundamental and structural problems with the current child welfare system in Canada. The following paper will examine the relationship between adolescent pregnancy and child welfare, investigate concerns with the current child welfare system, and look to the Convention on the Rights of the Child as a framework for conceptualizing alternative approaches.
\end{abstract}

learned anything about how to be a parent so I think I passed that on to my kids [...] Now it's my grandchildren, my great-grandchildren were taken" (Killington, 2002, p. 28).

In tracing these stories, an alarming statistical trend emerges, linking the issue of adolescent pregnancy to that of child welfare. Adolescent pregnancy in Canada is highest among disadvantaged socio-economic groups, and is a particular health concern for young Aboriginal women. It is four times higher among First Nations adolescents, twelve times higher in Inuit communities, and eighteen times higher on reserves than in the general population (Canadian Institute of Child Health, 2000). Furthermore, adolescents who have been involved in the child welfare system are more likely to become pregnant teenagers (Canadian Institute of Child Health, 2000). At the same time, children of adolescent mothers are at greater risk of abuse and neglect and are more likely to be taken into care (Canadian Institute of Child Health, 2000).

This relationship provides a starting point from which to explore some of the larger structural problems of the Canadian child welfare system. Recently, a human rights complaint by the Assembly of First Nations and the First Nations Child and Family Caring Society of Canada 
(Assembly of First Nations, 2006) signaled the concerning over-representation of Aboriginal children in the child welfare system. It revealed that Aboriginal children - ie. those of Inuit, Métis, or First Nations ancestry - are three times more likely to be under the care of child welfare authorities (p.1). Moreover, Aboriginal children constitute up to $40 \%$ of the 76,000 young people placed in foster care in Canada (Blackstock, Trocmé \& Bennett, 2004; Blackstock \& Trocmé, 2005). These numbers become a socioeconomic rights issue when viewed in light of the fact that the majority of Aboriginal children are removed from their families for reasons of neglect, the form of maltreatment that is most closely linked to poverty (Assembly of First Nations, 2006). While the nature of the human rights complaint focused on discrimination in regard to funding allocated to First Nations child and family service providers, it has highlighted a host of structural and systemic concerns that underpin the overrepresentation of Aboriginal children in the child welfare system. In addition to inequitable funding levels, the current child welfare system raises serious questions as it places a greater focus on the placement of Aboriginal children in foster care, and is limited in its efforts to address the root causes of neglect (Assembly of First Nations, 2006). Aboriginal communities across the country are strongly opposed to the placement of Aboriginal children in non-Aboriginal foster homes, and have underlined the importance of strengthening families and communities to better care for children (First Nations Child \& Family Caring Society of Canada, 2005a).

\section{Theoretical Starting Points}

Several perspectives offer guidance in approaching these concerns. These approaches - namely, the Aboriginal approach, the child-centred approach, the health promotion approach, and the feminist relational approach - provide a starting point from which to understand the relationship between child welfare and adolescent pregnancy, and from which to explore solutions.

\section{An Aboriginal Approach}

Aboriginal values and belief systems, which emphasize holistic approaches and intergenerational responsibility, provide an important perspective through which to assess adolescent pregnancy and child welfare in Aboriginal communities. The saying that "it takes a community to raise a child," (Health Canada, 1997) for example, underlines the idea of childrearing as a communal practice that is done by the extended family and whole community (Health Canada, 1997, p. 5). Furthermore, inter-generational understandings of responsibility provide insight and awareness into the importance of relationships. Narratives reveal that women were viewed as "keepers of the culture;" it is the grandmothers who "held onto what they could of [their] identity as a People," who "kept the fire [from growing] dim," who "ensured that [Aboriginal people] would be able to know who [they were]" (Fiske, 1993). As such, identity and responsibility are understood in relational terms. As one woman explains, "we were taught that the time we are in is only borrowed from future generations - generations yet unborn. Our thoughts, words and actions impact seven generations from now. It is these children held sacred by our Mother Earth for whom we must leave a true fire" (Fiske, 1993).

\section{A Child-Centred Approach}

A child-centred approach to the cycle of child welfare and adolescent pregnancy highlights the importance of families and communities in children's social-emotional development, self-esteem building, and identity formation. Carol Phillips, a researcher in early childhood development, has examined a process of socialization identified as "enculturation" (Greenwood, 2003). This process, she explains, whereby the child is integrated into his or her birth community, and whereby "families enable children to know and understand a [culture's] values, attitudes, beliefs and behaviours," (Greenwood, 2003) is critical to children's healthy growth and development (p.2). Moreover, Phillips has noted the need to positively promote Aboriginal children's identity and self-esteem given the history and impact of colonialism (p.5).

Emmy Werner has similarly emphasized the importance of fostering trusting relationships in early childhood. "The ability to trust," she explains, "learned early in a child's life, lays the foundation for resiliency, [...] the ability to bounce back when times get tough" (Greenwood, 2003, p. 2). To this point, H.N. Chang has underlined that "an environment of positive relationships, role models and recognition of a child's family and community enhances the self-esteem of the child" (Greenwood, 2003, p. 7). As a result, disruptions in family and community relationships have been directly linked to negative mental health consequences, and to issues such as adolescent pregnancy and child welfare. For example, in Aboriginal communities, the inter-generational breakdown has been associated with problems of alienation, substance abuse and the early onset of sexual activity (Canadian Institute of Child Health, 2000, p. 30).

\section{A Health Promotion Approach}

It is important to note that the intentions of this paper are framed by a focus directed at improving determinants of health. A health promotion approach maintains that "pregnancy and motherhood can be much more positive experiences if the woman is fully developed physically, mentally, emotionally and [if] she has the resources and support [that] she and her child need" (Archibald, 2004, 
p. 30). As such, this discussion emphasizes the need to respect young women's choices, while providing them with the support required "to make informed [and] healthy decisions." (Archibald, 2004, p. 30). A health promotion approach thus underlines the importance of "programs that address teen pregnancy prevention in the context of healthy sexuality," and "strategies that use the determinants of healthy development to increase the health and well-being of all children." (Canadian Institute of Child Health, 2000, p. 20).

\section{A Feminist Relational Approach}

Finally, as Colleen Sheppard explains, a key theme in feminist theory is "the need to situate legal rights within a web of social relationships" (Sheppard, 2004, p. 17). This recognition of interdependence forms the basis of the feminist relational approach, which was first articulated by Carol Gilligan. Gilligan's perspective seeks to challenge the individual self of classical liberalism by "seeing a world comprised of relationships rather than of people standing alone, a world that coheres through human connection rather than through systems of rules" (Gilligan, 1982, p. 29). In formulating her theory centered upon an "ethic of care," Gilligan suggests that women relate more to a moral framework that sees "the actors in the dilemma arrayed not as opponents in a contest of rights, but as members of a network of relationships on whose continuation they all depend" (p. 30). Thus, the focus shifts from separation to sustaining connection, as Gilligan maintains that "in the different voice of women lies the truth of an ethic of care, the tie between relationship and responsibility, and the origins of aggression in the failure of connection" (Gillian, 1982, p. 173).

Building upon this idea, Jennifer Nedelsky suggests a reconceptualization of autonomy that focuses on "the emergence of autonomy through relationship with others" (Nedelsky, 1989, p. 13). This awareness highlights the role of relationships in providing the "support and guidance necessary for the development and experience of autonomy." Looking to the parent-child relationship as a prime example of this reality, Nedelsky posits a perspective that acknowledges "relatedness [as a] literal precondition of autonomy, and interdependence [as] a constant component of autonomy" (p.108).

In the context of adolescent pregnancy and child welfare, the importance of relationship emerges very clearly in light of the intergenerational transmission of disadvantage, and the effects of ruptured relationships upon early childhood development. The role of families and communities in supporting young women's autonomy and decision-making also appears as an important variable in ensuring healthy choices.
These perspectives emphasize the need to empower children, youth, families, and communities for healthier outcomes. They underline the importance of promoting child welfare through prevention strategies that seek to address root causes, such as poverty and social dislocation, rather than simply relying on protection strategies that respond to symptoms as isolated events. Moreover, they highlight the importance of providing support services for young mothers, and the need to strengthen rather than disrupt families. Unfortunately, while child welfare experts and social workers have increasingly supported community-based interventions, changes in the legal discourse around child welfare have been slow to follow (Greenwood, 2003, p. 117). The need to develop a legal framework for change thus presents itself as integral step in promoting real and effective policy solutions.

As such, the phenomenon of adolescent pregnancy and its relationship to child welfare in Aboriginal communities provides a useful lens through which to understand fundamental and structural problems with the current child welfare system in Canada. The following paper examines the relationship between adolescent pregnancy and child welfare, investigates concern with the current child welfare system, and looks to the Convention on the Rights of the Child as a framework for conceptualizing alternative approaches.

\section{PART I: The Phenomenon of Adolescent Pregnancy and its Relationship to Child Welfare}

\section{A) The Consequences of Adolescent Pregnancy Among Aboriginal Youth for Adolescent Mothers, Children and Society}

As noted above, the rate of adolescent pregnancy among Aboriginal youth, both on and off-reserve, is significantly higher than that among non-Aboriginal youth (Canadian Institute of Child Health, 2000, p. x). In many of these situations, young mothers are able to build "satisfactory lives for themselves and their children" (Canadian Institute of Child Health, 2000, p. ix). Moreover, youth pregnancies may not be stigmatized due to the cultural valuing of all infants that exists in communities. Nevertheless, adolescent pregnancy often involves numerous consequences for adolescent mothers, their children, and society. Studies have indicated that adolescent mothers are "less likely to complete their education, more likely to experience isolation and homelessness, less likely to develop good parenting skills, and more likely to transfer their own history of childhood abuse and neglect to their [children]" (Canadian Institute of Child Health, 2000, p. ix). Similarly, early childbearing 
entails health risks for babies; pre-mature birth and low birth weight are common (p. ix), and the infant mortality rate is 60 percent higher (p.8). Children of adolescent mothers face a greater chance of "early childhood injury, acute illness, mental health problems, and eventual involvement in the criminal justice system" (p. ix). The relationship to neglect emerges given that Aboriginal adolescent mothers "are more disposed to substance abuse while pregnant and are less likely to be properly nourished or to breast feed their babies" (Canadian Institute of Child Health, 2000). Finally, the social impact of adolescent pregnancy is evidenced by increased rates of "school drop-out, incarceration, poverty, child abuse, and children taken into care" (Canadian Institute of Child Health, 2000). Notably, many of these effects are interconnected and inter-generational (Canadian Institute of Child Health, 2000).

\section{B) The Relationship between Adolescent Pregnancy and Child Welfare}

These consequences highlight the complex relationship between adolescent pregnancy and child welfare. Studies indicate that adolescents who have been involved in the child welfare system are more likely to become pregnant teenagers, and that the children of adolescent mothers face a greater risk of being taken into care (Canadian Institute of Child Health, 2000). Why is this? To begin with, adolescent mothers are more likely to suffer from the socioeconomic inequalities which contribute to conditions of neglect, such as poverty and lack of housing (Kirmayer, Brass \& Tait, 2000, p. 607). For example, "homelessness is twice as likely by the age of 33 for teenage mothers than for older ones" (Canadian Institute of Child Health, 2000, p. 7). In addition, it has been documented that "the pressures teen parents face predisposes them to child abuse and neglect" (Canadian Institute of Child Health, 2000, p. 7).

The effect of assimilationist policies upon Aboriginal communities further compounds this problem, as the development of parenting skills becomes difficult "within communities in which the extended family has broken down and there is no one to turn to for advice and support" (Canadian Institute of Child Health, 2000, p. 7). As one mother explained, her experiences growing up in foster care led to parenting difficulties; "when you are part of the system yourself you're never given any assistance or any structure on what a mom role is about, especially if you grew up in 10 or 14 different homes. How can you get structure like that as an adult and try to raise your own kids?" (Killington, 2002, p. 15).

Similarly, the lack of enculturation that many Aboriginal children experience due to non-Aboriginal foster placements has been linked to negative selfperceptions among adolescent mothers (Bent, Josephson
\& Kelly, 2004). The "transition from childhood to adulthood" has been identified as a critical time of "identity formation" (pp. 83-84). Social science research has indicated that "minority group adolescents who reach [a] stage of cultural identity achievement [...] develop a stronger sense of self and a more positive self-concept" (pp. 83-84). Consequently, under the stress of early parenting, adolescent mothers who have developed a negative self-concept due to lack of enculturation exhibit an increased risk of psychosocial problems, which contribute to greater difficulties with child-rearing, and increased rates of child abuse (pp. 83-84).

\section{C) Mother-Child Narratives and the Transmission of Disadvantages}

The relationship between adolescent pregnancy and child welfare highlights the ways in which narratives of disadvantage are transmitted from mother to child. The cyclical nature of socioeconomic inequality further underlines the importance of empowering young women to shift this narrative. Strengthening relationships between children, mothers, families and communities, through support and services such as counseling, thus becomes critical in ending stories of dislocation.

For example, research has found "that abusive parents are more likely than nonabusive parents to have been abused themselves, that child abuse and family violence are intergenerational in nature, and that women who were sexually abused are much more likely than nonabused women to have children who are physically and sexually abused" (Boyer \& Fine, 1992, p. 4). While not all parents replicate abusive pasts, these risk factors merit attention in light of the ongoing relationship between adolescent pregnancy, problematic parenting behaviours, and prior experiences of sexual abuse (Boyer \& Fine, 1992). Similarly, mothers recovering from drug and alcohol addictions reported "significantly higher levels of adversive childhood experiences, [negative home environments,] psychological distress, and the use of problemative parenting behaviours" (Harmer, Mertin \& Sanderson, 1999, p. 421). Preventive, rather than simply protective, services, thus become critical in preventing abuse before it happens and in addressing larger cycles of disadvantage.

\section{D) Factors which contribute to adolescent pregnancy}

Many of the causes of adolescent pregnancy are linked to socioeconomic inequalities which contribute to the exclusion, alienation and ill-health of Aboriginal children and youth. Furthermore, increased rates of adolescent pregnancy and single motherhood coincide with the growing feminization of poverty, particularly for young women living off reserve. Recent medical reports have highlighted the connection between health status 
and socioeconomic disadvantage, identifying the "young female face of poverty" as a public health concern (Postl, 1997, pp. 1655-1656). As a result, such conditions have given rise to neglect, substance abuse, and the rupture of family relationships. These realities feed into the causes of adolescent pregnancy, which include emotional needs, risk-taking behaviours, and lack of self-esteem.

\section{Emotional Needs}

In a recent study, adolescent mothers cited feelings of alienation, "the desire to re-create a family," and the need for "love and attention" as motivating factors behind their choice to have a baby (Archibald, 2004). The study concluded that "deficits in family life can contribute to a need for love and belonging that can lead alienated young girls to believe that having a baby of their own will fill the emotional gap and give them a place and purpose in life" (Canadian Institute of Child Health, 2000, p.17).

\section{Risk-Taking Behaviours}

Studies on risk-taking behaviour have similarly suggested that feelings of alienation increase the risk of pregnancy among young women (Canadian Institute of Child Health, 2000, p. 7). More specifically, findings indicate that "women who spent any time living in foster homes or with relatives other than parents during childhood have an elevated risk of engaging in high-risk sexual behaviours" (Hollander, 2002, p. 55). In addition, adolescents who have experienced sexual abuse, or who have been involved in the child welfare system, are more likely to begin sexual intercourse earlier, less likely to practice contraception (Boyer \& Fine, 1992, p. 4) and more likely to engage in substance abuse (Canadian Institute of Child Health, 2000, p. 7; Canadian Institute for Child Health, 2000, p. 17).

\section{Lack of Self Esteem}

While lack of access to contraception was an issue for some teenage mothers, a larger number of young women expressed an unwillingness to insist upon birth control due to lack of self-esteem (Archibald, 2004, p. 5). These findings are extremely disconcerting, and highlight the important relationship between enculturation, family support and self-esteem formation.

As such, these factors highlight the intergenerational and systemic nature of the relationship between adolescent pregnancy and child welfare. The growing number of Aboriginal children taken into care, alongside the spiraling rates of adolescent pregnancy and poverty in Aboriginal communities, reveal a cycle of harm that extends beyond isolated individuals - that is located in the rupture of family and community-level support systems and relations.

\section{PART II: The Role of Law in Responding to the Needs of Aboriginal Children and Youth: A Critical Look at the Current Child Welfare System in Canada}

Social service providers, Aboriginal communities, and government review bodies have heavily criticized the current child welfare framework in Canada. Concerns have centered around funding and jurisdiction incongruities, the current system's focus on childremoval, and the widespread lack of culturally appropriate services. These issues have resulted in a general perception of the child welfare system as an extension of the residential school system.

\section{A) Aboriginal Child Welfare in Canada: The Child Welfare Framework}

The complex legislative framework of the child welfare system in Canada has contributed to its problematic history and to a growing disconnect between funding and jurisdiction. Under the constitutional division of powers, funding for child welfare services off reserve is the responsibility of provincial and territorial governments, whereas, due to the Indian Act, funding for child welfare services on reserve to status Indian children remains the responsibility of the federal government (First Nations Child \& Family Caring Society of Canada, 2005, p. 107). The system's adversarial relationship with Aboriginal communities was established from the outset, as it organized a mass removal of Aboriginal children from their homes and communities, termed the " 60 s scoop" (First Nations Child \& Family Caring Society of Canada, 2005, p. 107). This traditional focus on removal as the only response to child maltreatment, rather than prevention or family-support services, was heavily criticized and led to the development of First Nations child and family service agencies (First Nations Child \& Family Caring Society of Canada, 2005, p. 108).

During the 1990s, restrictions on "the development of Aboriginal child agencies serving onreserve residents" were lifted by the federal government and a national funding formula, known as Directive 20-1 Chapter 5, was implemented (First Nations Child \& Family Caring Society of Canada, 2005). The directive was designed to provide funding for on-reserve child welfare agencies, however, it "requires that First Nations agencies work pursuant to provincial and territorial child welfare statutes." It generally operates across Canada, with the exception of Ontario, which has a separate funding agreement (First Nations Child \& Family Caring Society of Canada, 2005, p. 107). As a result of the directive, Aboriginal child and family service agencies that operate under their own child welfare jurisdiction are ineligible for funding (First Nations Child \& Family 
Caring Society of Canada, 2005a, p. 107). Moreover, the criteria imposed under provincial and territorial child welfare statutes have been identified as problematic, as Aboriginal agencies struggle to reconcile "services that reflect the holistic, interdependent, and communal rights framework of the cultural communities they serve with individual rights-based child welfare statutes" (First Nations Child \& Family Caring Society of Canada, 2005a).

\section{The "Disconnect" between Jurisdiction and Funding}

In 1998, the Auditor General of Canada noted a "disconnect between funding and jurisdiction," reporting an "inequity of services to Status Indian children in Canada" Blackstock, Clarke, Cullen, D'Hondt \& Formsma, 2004, p. 160; Auditor General of Canada, 1988, s. 14.76). Under the regime set up by the directive, "funding levels are not linked to the content of provincial and territorial child welfare statutes." Difficulties arise when "provinces and territories change their legislation, [as] there is no concordant review of funding levels to ensure that adequate resources are provided to First Nations child welfare agencies to meet new statutory responsibilities" (Greenwood, 2003, p. 108). Consequently, a 2000 national review of child welfare agencies discovered that "on average, First Nations child and family service agencies receive $22 \%$ less funding per child than their provincial equivalents" (Blackstock \& Trocmé, 2005; MacDonald \& Ladd, 2005). This is especially problematic given the higher level of child welfare needs on-reserve (Blackstock \& Trocmé, 2005; MacDonald \& Ladd, 2005).

\section{B) Critiques of the Current Child Welfare System}

More generally, assessments of the current child welfare model have observed failures of the protection paradigm itself, and have recommended an alternative framework based on community wellness (Bellefeuille \& Ricks, 2003, p. 23). Such a model, "in contrast to the individual needs-based protection approach, [...] implies a need to broaden traditional child protection policy to respond to the well-being of children generally, not just to those children at immediate "risk"”" (Bellefeuill \& Ricks, 2003, p. 39). Drawing from the health promotion approach, the community wellness paradigm recognizes the systemic vulnerability of Aboriginal children, understanding "all problems and causes [...] as a problem of larger social structures." As a result, it calls for the "[reconceptualization of] child welfare," and for the development of "empowering health promotion strategies that acknowledge and reinforce the capacity of communities for self-care and change" (Bellefeuill \& Ricks, 2003, p. 39).

\section{Addressing Symptoms Rather than Causes}

The current protection model, for example, has been heavily criticized for its emphasis on child removal rather than preventive services Blackstock \& Trocmé, 2005 , p. 7). Resources and support are sorely needed in Aboriginal communities, and child welfare agencies are poorly equipped to deal with the systemic drivers of child maltreatment, which include poverty, unemployment, inadequate housing, and intergenerational trauma (Greenwood, 2003; Blackstock \& Trocmé, 2005; and Blackstock, Trocmé \& Bennett, 2004). This is particularly relevant given that "over half of Aboriginal cases [involve] neglect," the form of maltreatment most closely associated with poverty, "whereas neglect [is] found in only half as many non-Aboriginal cases" (Greenwood, 2003, p. 110).

The problem with addressing symptoms rather than causes becomes abundantly clear in the case of fetal alcohol syndrome (FAS). Given the high incidence of substance abuse on reserves, Aboriginal children face a significantly increased risk of FAS (Marino \& Fine, 2003). The legal response to substance abuse among pregnant adolescents has focused on the removal of infants after they have been born with FAS. This is of little help to the children who consequently suffer permanent mental and physical defects (Marino \& Fine, 2003). Support services and treatment programs to prevent substance abuse among pregnant adolescents, on the other hand, would promote healthy maternal and infant outcomes, while improving children's long-term well-being (Health Canada, 1997).

Furthermore, the harm that occurs within the child welfare system must not be underestimated. Children are often moved from one foster-placement to another, and "accounts of deprivation in care systems lead to reports from young people that they can no longer trust people in human relationships" (Bagley, 1985, p. 67). The impact of such experiences is severe, as a review in Alberta indicated that nearly a fifth of children in government care had attempted suicide or acts of deliberate selfharm (Bagley, 1985, p. 69). Frequent abuse within the child welfare system has also led to mistrust by the very children it is meant to protect. As one mother who had grown up in foster care expressed, "to them you're either just a pay cheque, a baby-sitter, house-cleaner or plaything" (Killington, 2002, p.15). While the creation of Aboriginal agencies on reserves has reduced the constant re-placement of Aboriginal children, important gaps in off-reserve services continue to exist.

\section{The Importance of Culturally Relevant Services}

Concerns have also focused on the lack of culturally appropriate services for Aboriginal families living off- 
reserve (First Nations Child \& Family Caring Society of Canada, 2005a). Mothers, for example, have "reported experiencing racism and discrimination when dealing with the mainstream government child welfare system, both in a larger structural sense and also in their own personal interactions and involvements with individual workers" (Killington, 2002, p. 28). Culturally relevant services thus play an important role in shaping positive and constructive relationships between the child welfare system, and the children and families it serves.

Similarly, social science research has underlined the importance of enculturation for children's development, recommending that children be "cared for within [the] community whenever possible" (Greenwood, 2003, p. 108). When removal is necessary, the lack of culturallyappropriate placements has been raised as an important issue. While few provinces collect data on cultural placement match, a 1998 report by the Children's Commissioner of $\mathrm{BC}$ found that "only $2.5 \%$ of Aboriginal children were placed in Aboriginal foster homes despite a statutory requirement to give preference to extended family and culturally based placements" (Blackstock, Clarke, Cullen, D'Hondt, \& Formsma, 2004, p. 155). The need for culturally relevant services thus emerges as a critical step in conceptualizing a system which promotes healthy outcomes for children and families (Greenwood, 2003, p. 108).

\section{Prioritizing the Needs of Children and Families}

Ultimately, these critiques are not new or surprising. In 2000, the First Nations Child and Family Services Joint National Policy Review published a wide range of recommendations. These included "supporting First Nations self-government aspirations in child welfare, [and increasing] levels and flexibility of funding regimes to promote community capacity to care for children, through community development and prevention programming." (First Nations Child \& Family Caring Society of Canada, 2005b, p.6). All of these recommendations remain unimplemented (First Nations Child \& Family Caring Society of Canada, 2005b, p.6). As the recent Wen: de report expressed, "the urgent needs of children and families are falling through government jurisdictional cracks. Funding formulas and jurisdictional arrangements must put the needs of children and families first" (First Nations Child \& Family Caring Society of Canada, 2005a, p. 88). The current legislative framework of the Canadian child welfare system has been assessed - by parties on all sides - as a structural failure in dire need of reform. Legal responses must prioritize the needs of children and families, while recognizing the impact of legislative incongruities on lives and relationships.

\section{C) The Child Welfare System and its Relationship to Colonialism}

The overrepresentation of Aboriginal children within the child welfare system has further been perceived as a "problem rooted in a pervasive history of discrimination and colonization" (Blackstock \& Trocmé, 2005, p.34). To many Aboriginal people, the child welfare system represents a painful history of Aboriginal children being stolen from their homes. As an account by Tikinagan Child and Family Services explains, "our [story] as Native people includes the loss of hundreds of our children from their loving families and communities" (Brubacher, 2006). The report emphasizes the importance of reclaiming the past and "[bringing] lost children back home" (p.9). The struggle thus becomes one in which Aboriginal communities and Aboriginal-based child and family service agencies "reaffirm [their] right to care for [their] own children" (p. 17).

The child welfare system has similarly been perceived as an extension of the assimilationist policies embodied by the residential school system. The legacy of child-removal continues to impact Aboriginal communities on a massive scale. It is estimated that "there are as many as three times more Aboriginal children in the care of child welfare authorities now than there were placed in residential schools at the height of their operation in the 1940s" (Blackstock \& Trocmé, 2005, p.1). More disturbingly, between 1995 and 2001, data indicate a " $71.5 \%$ increase in the number of Status Indian children on reserve being placed in child welfare" (Blackstock, Clarke, Cullen, D’Hondt, \& Formsma, 2004, p. 156). These numbers testify to the "past, and current, multi-generational and multi-dimensional impacts of colonization on Indigenous children, youth and families" (Blackstock, Cross, George, Brown, \& Formsma, 2006, p. 4). Furthermore, they attest to the ways in which the rupture of families and communities has resulted in dysfunction, separation, "splintered relationships," and an enormous loss in individual and collective identity (Killington, 2002, p. 28; Blackstock, Clarke, Cullen, D'Hondt, \& Formsma, 2004, p. 21). As such, the traditional child welfare system as a legal response has contributed to the "multigenerational grief, trauma and displacement" among Aboriginal peoples (Greenwood, 2003, p. 106).

Moreover, current child welfare models continue to reflect colonial patterns, in terms of both the imposition of dominant cultural values and practices in relation to child-rearing, and the consequent devaluation of Aboriginal values and practices (Kline, 1993, p. 306). For example, Marlee Kline maintains that "First Nation women are particularly vulnerable to being constructed 
by the courts as 'bad mothers' in child protection proceedings, and to having their children taken away as a result" (p. 340). As such, she argues that the "ideology of motherhood" in child protection cases essentially blames individual women for the difficulties that they encounter in parenting, while ignoring the connection between these difficulties and the history of colonialism (p. 306).

\section{PART III: The Convention on the Rights of the Child: A Framework for Conceptualizing Alternative Approaches to Child Welfare}

In conceptualizing alternative approaches to legal intervention, a human-rights framework offers useful ideas and guidance. In particular, given the relationship between adolescent pregnancy and child welfare, the Convention on the Rights of the Child (CRC) provides an effective starting point for promoting the well-being of children and youth. As a source of international law, the convention envisages children as important participants in society, articulates a set of rights specific to children's needs, and establishes a broad range of state responsibilities (Blackstock, Clarke, Cullen, D'Hondt, \& Formsma, 2004, p. 22). Furthermore, the CRC is "the first international treaty body instrument to specifically include protections for indigenous children" (Blackstock, Clarke, Cullen, D'Hondt, \& Formsma, 2004, p. 22). The following discussion aims to apply the convention to the current child welfare system in order to outline a legal framework for reform. In doing so, it remains important to approach this analysis with the intention of taking Canada's legal obligations seriously. This is especially relevant in light of the fact that the last residential school did not close until 1996, five years after Canada signed the CRC (Blackstock, Clarke, Cullen, D'Hondt, \& Formsma, 2004, p.153).

\section{The Best Interests of the Child}

One of the central principles of the convention is articulated in article 3, which establishes that "in all actions concerning children, whether undertaken by public or private social welfare institutions, courts of law, administrative authorities or legislative bodies, the best interests of the child shall be a primary consideration" (Convention on the Rights of the Child, 1989). Applied to the current child welfare system in Canada, this principle underlines the need to respond to the recommendations of national policy reviews, First Nations child and family service agencies, and social workers. For example, child welfare practitioners have stressed the importance of "community empowerment approaches to child welfare" in ensuring the well-being of children (Walmsley, 2004, p. 63). Critiques of the protection paradigm by those working in the field must be taken seriously and considered in the context of legislative reform. Furthermore, given the overwhelming evidence of the system's structural failures, article 3 demands that immediate steps be taken to promote the best interests of Aboriginal children in Canada.

It is important to note that the best interests principle has not always been interpreted in a culturally neutral way. Aboriginal perspectives maintain that "the notion of the child and her best interests, as separate and distinct from her family, community and culture, is one that has its roots in the individualist orientation of European culture" Richard, 2004, p. 109). Moreover, within Canadian courts, Kline argues that the best interests ideology has "[portrayed] the apprehension and placement of First Nations children away from their families and communities as natural, necessary, and legitimate, rather than coercive and destructive" (Kline, 1992, p. 375). As such, judicial decisions have often minimized the relevance of identity and culture to Aboriginal children's development (Kline, 1992, p. 375). A more relational understanding of the best interests principle suggests the need to support collective approaches that promote children's well-being through belonging and community wellness (Richard, 2004, p. 103).

\section{The Right to Non-Discrimination}

The principle of equality is set out in article 2 of the $\mathrm{CRC}$, which declares that "states parties shall respect and ensure the rights set forth in the [Convention] to each child within their jurisdiction without discrimination of any kind" (Convention on the Rights of the Child, 1989, Art. 2(1)). This article underlines the need to address discrimination against Aboriginal children in Canada. The UN Committee on the Rights of the Child has expressed concern at the situation of Canadian Aboriginal children, noting that they continue to face significant and disproportionate levels of risks in areas such as education, youth justice, health and poverty (Committee on the Rights of the Child, 2003). More specifically, in the context of child welfare, article 2 highlights the need to remedy the inadequate funding of child and family service providers on reserves (Blackstock, Clarke, Cullen, D’Hondt, \& Formsma, 2004, p. 170). The current situation, where "First Nations child and family service agencies receive $22 \%$ less funding per child than their provincial equivalents" (Greenwood, 2003, p. 108), constitutes a clear case of discrimination against Aboriginal children and youth. As indicated earlier a Human Rights Complaint decrying discriminatory funding was jointly launched in 2006 by the Assembly of First Nations and the First Nations Child and Family Caring Society of Canada, a national nonprofit organization that advocates, networks and conducts research on behalf of approximately $120+$ mandated First 
Nations child welfare agencies across Canada (Assembly of First Nations, 2006).

\section{The Child's Right to Survival and Development}

Article 6 declares that "States Parties shall ensure to the maximum extent possible the survival and full development of the child" (Convention on the Rights of the Child, 1989, Art. 6(2)). This provision outlines the right of children "to realize their full potential, through a range of strategies from meeting their health, nutrition and education needs, to supporting their personal and social development" (First Nations Child \& Family Caring Society of Canada, 2005b, p. 4). As such, it requires that child development theories be taken into account, and that the importance of family, community, continuity of care and culture be recognized in child welfare policies. Nedelsky's idea of supporting autonomy through relationship further emphasizes the importance of human support networks for children's healthy development.

The Native Infant Program on Vancouver Island provides a successful example of an early intervention program for infants and their families. Based upon early childhood development principles, the homebased program targets children from 0 to 4 years of age (Mayfield \& Davies, 1984, p. 450). Focusing on "the early correction of departures from good health, and [the] prevention of social problems," the Native Infant Program combines support with education, integrating both "traditional cultural and present childrearing practices" (Mayfield \& Davies, 1984, p. 450). Furthermore, it "provides children with experiences and services which enhance their early development by encouraging and helping parents to develop [the] skills necessary to provide meaningful experiences for their children" (Mayfield \& Davies, 1984, p. 450). As such, the Native Infant Program constitutes an essential resource for adolescent mothers, and provides a useful model for child welfare strategies. In supporting parents' abilities to best care for their children, it prioritizes healthy child development during the critical early years, and encourages positive outcomes.

\section{The Right of Children to be Heard}

One of the most fundamental principles contained in the convention is the right of children to be heard. Article 12 of the CRC establishes the right of children to "express [their] views freely in all matters affecting [them]," and provides that "the views of the child [shall be] given due weight" (Convention on the Rights of the Child, 1989, Art. 1.2(1)). Furthermore, article 12 explicitly underlines the importance of providing children "with the opportunity to be heard in any judicial or administrative proceeding affecting [them]" (Convention on the Rights of the Child, 1989, Art. 1.2(1)). This provision has been understood to mean "that children are not passive recipients, but actors contributing actively to the decisions that affect their lives" (First Nations Child \& Family Caring Society of Canada, 2005b). In the context of child welfare, article 12 highlights the duty to consult children and youth when designing policies and programs that affect them. More particularly, it underlines the need to listen to the voices of children and youth who have come into contact with the child welfare system. The high number of youth suicides while under care (Bagley, 1985, p. 69), the testimonies of abuse within the foster system, and the voices of pregnant adolescents who cite emotional needs as one of the motivating factors behind their choices, speak to the importance of incorporating young people's perspectives. Situating legal responses within the context of young people's experiences is critical to understanding challenges and developing effective strategies for change.

\section{The Right to Culture}

The right to culture is articulated in article 30 of the convention, which states that a child "who is indigenous shall not be denied the right, in community with other members of his or her group, to enjoy his or her own culture, to profess and practice her or her own religion, or to use his or her own language" (Convention on the Rights of the Child, 1989, Art. 30). This provision reflects the importance of building a child welfare system that focuses on prevention, that adequately funds Aboriginal service providers, and that supports the efforts of families and communities to safely care for their children. Moreover, it emphasizes the need to prioritize cultural placement in order to maintain children's connections with extended family, culture and community (First Nations Child \& Family Caring Society of Canada, 2005b).

In addition, the right to culture underlines the importance of ensuring "universal access to culturallybased child welfare services" (Blackstock, Clarke, Cullen, D’Hondt, \& Formsma, 2004, p. 170). For example, the Manitoba Aboriginal Justice Inquiry Child Welfare Initiative provides a promising model. The initiative "allows residents of Manitoba to choose [from] four culturally-based child welfare authorities," which include Northern First Nations, Southern First Nations, Métis, and Mainstream. As a result, given that "over $70 \%$ of children in care [in Manitoba] are Aboriginal, $86 \%$ of families are choosing their culturally based authority" (Blackstock \& Trocmé, 2005). The success of this program illustrates the role of cultural sensitivity in shaping positive relationships with the child welfare system and in promoting healthier outcomes. 


\section{The Right of Every Child to an Adequate Standard of Living}

The importance of ensuring children's social and economic rights emerges in article 27 of the convention, which establishes "the right of every child to a standard of living adequate for the child's physical, mental, spiritual, moral and social development" (Convention on the Rights of the Child, 1989, Art. 27(1)). The content of this obligation further requires that states "assist parents [and] provide material assistance and support programmes, particularly with regard to nutrition, clothing and housing" (Convention on the Rights of the Child, 1989, Art. 27(3)). This provision underlines the responsibility of governments to implement child welfare strategies that address the systemic drivers of neglect. For Aboriginal children in Canada, article 27 highlights the need for preventive services that respond to widespread issues such as inadequate housing, poverty, and substance abuse.

\section{The Right to Recovery and Reintegration}

Finally, article 39 maintains that "states parties shall take all appropriate measures to promote physical and psychological recovery and social integration of a child victim of $[. .$.$] neglect, exploitation, or abuse" (Convention$ on the Rights of the Child, 1989, Art. 39). The provision specifies that "such recovery and reintegration shall take place in an environment which fosters the health, self-respect and dignity of the child" (Convention on the Rights of the Child, 1989, Art. 39). This principle speaks directly to the relationship between adolescent pregnancy and child welfare, emphasizing the need to address the intergenerational transmission of disadvantage. It articulates the responsibility of Canada to address the long-term impact of assimilationist policies on Aboriginal communities and children. Moreover, it reflects the need to question colonial patterns that continue to inform current child welfare models and decision-making. A prevention and community wellness-based child welfare framework thus emerges as essential to the recovery and social integration of the youngest generation, and of generations to come.

\section{Conclusion}

The relationship between adolescent pregnancy and child welfare thus provides a vantage point from which to understand some of the larger problems of the current child welfare system in Canada. It tells a story of intergenerational hurt and loss; of disadvantage transmitted from mother to child. Consequently, the voices of young women and their children are critical in conceptualizing a legal - and human - response to the cycle of failed responsibilities that adolescent pregnancy and the over-representation of Aboriginal children in the child welfare system reflect.

Service providers emphasize that "the care of a child does not occur in isolation: an Aboriginal child lives within a family, a community, a Nation, a province, and a country" (Greenwood, 2003, p. 7). In this context, and in light of the fundamental impact of a child's early years and experiences on her development, "it is critical that we 'get it right' as leaders, policy makers, experts and practitioners" (Greenwood, 2003, p. 7).

In a recent report on reconciliation in child welfare, the authors use the analogy of a journey down the river to describe the transformation that is needed. The profession, they claim - from legislators to social workers - must "courageously [reach] within itself to look at what aspects of child welfare [work] for, and against, the well-being of Indigenous children and youth." It must "[explore] the values and beliefs that [have] shaped the path the river has taken before identifying the touchstones necessary to build a foundation for an improved child welfare system" (Blackstock, Cross, George, Brown \& Formsma, 2006). Ultimately, the decision that a change in the direction of child welfare is needed "has already been taken" - by the Aboriginal children and youth who have paddled against the current and cried for change. It is they who believe that the life of a child can be different, that the system "can do better" - and it is long past time that we "[joined] them on the journey" (Blackstock, Cross, George, Brown \& Formsma, 2006, p. 6).

\section{References}

Assembly of First Nations. (2006). Leadership Action Plan on First Nations Child Welfare. Ottawa: The authors. Accessed from http://www.afn.ca/misc/afn-child.pdf.

Archibald, Linda. (2004). Teenage Pregnancy in Inuit Communities: Issues and Perspectives. Ottawa: Paukuutit Inuit Women's Association. Accessed from http://www.pauktuutit.ca/pdf/publications/pauktuutit/TeenPregnancy_e.pdf.

Auditor General of Canada. (1998). 1998 Report of the Auditor General of Canada: Department of Indian Affairs and Northern Development. Ottawa: Auditor General of Canada.

Bagley, Christopher. (1985). Child Abuse by Child Welfare System. Journal of Child Care, 2 (3), p. 67.

Bellefeuille, Gerar and Ricks, Frances. (2003). A Pathway to Restoration: From Child Protection to Community Wellness. Native Social Work Journal, 5, p. 23.

Bent, Kathy, Josephson, Wendy and Kelly, Barry. (2004). Effects of an Aboriginal Cultural Enrichment Program on Adolescent Mother's Self-Perceptions. First Peoples Child \& Family Review, 1(2), p. 83. 


\section{A Story of Their Own: Adolescent Pregnancy and Child Welfare in Aboriginal Communities}

Blackstock, C., S. Clarke, J. Cullen, J. D’Hondt, and J. Formsma. 2004. Keeping the Promise: The Convention on the Rights of the Child and the Lived Experiences of First Nations Children and Youth. Ottawa, ON: First Nations Child \& Family Caring Society of Canada. Accessed from http://www.fncfcs.com/docs/KeepingThePromise.pdf.

Blackstock, Cindy, Trocmé, Nico and Bennett, Marlyn. (2004). Child Maltreatment Investigations among Aboriginal and Non-Aboriginal Families in Canada. Violence Against Women, 10(8), p. 901.

Blackstock, Cindy \& Trocmé, Nico. (2005). Community Based Child Welfare for Aboriginal Children: Supporting Resilience through Structural Change. In M. Unger (Ed.), Pathways to Resilience: A Handbook of Theory, Methods and Interventions. Thousand Oaks, CA: Sage.

Blackstock, C., T. Cross, J. George, I. Brown, and J. Formsma. (2006). Touchstones of Hope for Indigenous Children, Youth, and Families. Ottawa, ON: First Nations Child \& Family Caring Society of Canada.

Brubacher, Maurice. (2006). Coming Home: the Story of Tikinagan Child and Family Services. Sioux Lookout, ON: Barney.

Boyer, Debra and Fine, David. (1992). Sexual Abuse as a Factor in Adolescent Pregnancy and Child Maltreatment. Family Planning Perspectives, 24 (1), p. 4.

Canadian Institute of Child Health. (2000). Pro-Action, Postponement, and Preparation/Support. Ottawa: CAPC/CPNP.

Committee on the Rights of the Child. (2003). Consideration of Reports Submitted by States Parties Under Article 44 of the Convention, CRC/C/15/Add.215.

Convention on the Rights of the Child, G.A. Res. 44/25, UN GAOR, (entered into force Nov.20, 1989).

First Nations Child \& Family Caring Society of Canada. (2005a). Wen:de We Are Coming To The Light Of Day. Ottawa: First Nations Child and Family Caring Society of Canada.

First Nations Child \& Family Caring Society of Canada. (2005b). United Nations Committee on the Rights of the Child, Non Discrimination and Diversity. Ottawa: First Nations Child and Family Caring Society of Canada.
Fiske, Jo-Anne. (1993). Children of the State Mother of the Nation: Aboriginal Women and the Ideology of Motherhood. Culture, 13(1), p. 17.

Greenwood, Margo. (2003). BC First Nations Children: Our Families, Our Communities, Our Future. Vancouver: BC First Nations Early Childhood Development Roundtable.

Harmer, Antoinette L. M., Mertin, Peter \& Sanderson, Jennifer. (1999). Influence of Negative Childhood Experiences on Psychological Functioning, Social Support, and Parenting for Mothers Recovering from Addiction. Child Abuse \& Neglect, 23(5), p. 421.

Hollander, D. (2002). Sexual Risks Are Increased for Women Who Were Ever In Foster or Kinship Care. Lancet, 34(1), p. 55 .

Gilligan, Carol. (1982). In a Different Voice: Psychological Theory and Women's Development. Cambridge: Harvard University Press.

Health Canada. (1997). It Takes a Community: Framework for the First Nations and Inuit Fetal Alcohol Syndrome and Fetal Alcohol Effects Initiative. Ottawa, Minister of Health.

Killington, Stephanie. (2002). Missing Voices: Mothers at risk for or experiencing apprehension in the child welfare system in BC. Vancouver: National Action Committee on the Status of Women.

Kirmayer, Laurence J., Brass, Gregory M. and Tait, Caroline L. (2000). The Mental Health of Aboriginal Peoples: Transformations of Identity and Community. Canadian Journal of Psychiatry, 45(7), 607.

Kline, Marlee. (1992). Child Welfare Law, "Best Interests of the Child" Ideology, and First Nations. Osgoode Hall Law Journal, 30, p. 375.

Kline, Marlee. (1993). Complicating the Ideology of Motherhood: Child Welfare Law and First Nations Women. Queen's Law Journal, 18, p. 306.

Macdonald, R. \& Ladd, P. (2000). Governance and First Nations Child and Family Services Joint National Policy Review Final Report. Prepared for: Assembly of First Nations with First Nations Child and Family Services Agency Representatives in Partnership with the Department of Indian and Northern Affairs and Northern Development. Ottawa: 


\section{First Peoples Child \& Family Review, Volume 3, Number 4, 2007}

Assembly of First Nations and Department of Indian and Northern Affairs and Northern Development.

Marino, Bradely S. and Fine, Katie S. (2003). Blueprints Pediatrics (4th Ed.). Philadelphia: Lippincott Williams \& Wilkins.

Mayfield, Margie I. and Davies, Gayle. (1984). An Early Intervention Program for Native Indian Infants and Their Families. Canadian Journal of Public Health, 75, p. 450.

Nedelsky, Jennifer. (1989). Reconceiving Autonomy: Sources, thoughts and possibilities. Yale Journal of Law \& Feminism, 1, p. 7.

Postl, Brian. (1997). It's time for Action. Canadian Medical Association Journal, 157(12), p. 1655.

Richard, Kenn. (2004). A Commentary Against Aboriginal to non-Aboriginal Adoption. First Peoples Child \& Family Review, 1(1), p. 101.

Sheppard, Colleen. (2004). Intimacy, Rights and the ParentChild Relationship: Rethinking Freedom of Association in Canada. National Journal of Constitutional Law, 16, p. 103.

Walmsley, Christopher. (2004). Talking about the Aboriginal Community: Child Protection Practitioners' Views. First Peoples Child \& Family Review, 1(1), p. 63. 